\title{
ENTERORRAFIAS EM PLANO APOSICIONAL CONVENCIONAL E COM ADESIVO À BASE DE CIANOACRILATO NO CÓLON DESCENDENTE DE EQÜINOS
}

\author{
CONVENTIONAL APPOSITIONAL PATTERN AND CYANOACRYLATE TISSUE \\ ADHESIVE IN DESCENDING COLON ENTERORRHAPHY IN HORSES
}

\author{
Claudia Acosta Duarte ${ }^{1}$ José Wanderley Cattelan $^{2}$ Antônio Carlos Alessi ${ }^{3}$ \\ Paula Pimentel Valente ${ }^{1}$ Andréa da Costa Aita ${ }^{1}$ Luciane Rasera ${ }^{1}$
}

RESUMO

Em eqüinos, as enterotomias no cólon descendente são necessárias para remover enterólitos, corpos estranhos e material alimentar compactado que não podem ser removidos por técnicas conservativas. Este segmento intestinal possui um suprimento sangüíneo pobre, além de predisposição a complicações pós-operatórias relacionadas à contaminação bacteriana. Assim, este estudo foi conduzido com o objetivo de efetuar avaliações clínicas e anatomopatológicas do emprego de adesivo tecidual à base de cianoacrilato no cólon descendente de eqüinos, comparando-o a uma técnica de sutura aposicional convencional. A intervenção cirúrgica foi realizada em 15 animais posicionados em decúbito lateral direito, através de laparotomia pelo flanco esquerdo, sob anestesia geral inalatória. Após a exteriorização do cólon descendente, foram realizadas duas enterotomias de cinco centímetros de extensão cada, distanciadas $20 \mathrm{~cm}$ uma da outra. Os animais foram aleatoriamente distribuídos em cinco tempos de observação de três animais cada e sacrificados aos três, sete, 14, 35 e 70 dias de pós-operatório. $O$ adesivo butil-2cianoacrilato e o fio de poliglactina 910 mostraram-se igualmente apropriados para uso em enterorrafias desse órgão, sendo que o fio de poliglactina 910 provocou inflamação inicial mais intensa que o cianoacrilato e, mais tardiamente, ambos causaram inflamação granulomatosa do tipo corpo estranho observada, primeiramente, junto ao fio de poliglactina 910 ( $7^{\circ}$ dia) e, a partir do $35^{\circ}$ dia, ao redor do cianoacrilato.

Palavras-chave: cianoacrilato, cólon descendente, eqüino

\section{SUMMARY}

The descending colon enterotomies in horses are necessary to remove enteroliths, foreign body and impacted

\begin{abstract}
material that can not be removed with conservative technique. This intestinal segment has a poor blood supply and the predisposition to post operation complications related to bacterium contamination. This trial was conducted in order to evaluate, clinically and anatomopathologically, the use of tissue adhesive of cyanoacrilate in the equine descending colon and to compare with an apposition pattern. Fifteen horses were used. Surgical intervention was done using laparotomy by the left flank, with the animals in right lateral recumbent position, under inhaler anesthesia. After exteriorization of the descending colon, two five-centimeter-long enterotomies were done, $20 \mathrm{~cm}$ apart one from the other. The horses were randomly distributed in five groups of three animals each. After human methods of euthanasia, necropsy was done with complete examination and documentation of sutured areas of the descending colon on post operation (days 3,7,14,35 and 70), one group at each time. The butyl-2-cyanoacrilate and the suture thread poliglactin 910 both showed that they are appropriate to be used in enterorrhaphies of this organ. The suture thread poliglactin 910 caused more intense initial inflamation compared to the cyanoacrilate, and later, both caused granulomatous inflammatory of the sort of foreign body. This was observed, firstly, in the suture thread poliglactin 910 (on day seven) and starting from the day 35 around cyanoacrilate.
\end{abstract}

Key words: cyanoacrylate, descending colon, horse

\section{INTRODUÇÃO}

As técnicas cirúrgicas para correção de afecções do cólon descendente de eqüinos incluem enterotomias, ressecção e anastomose intestinal ou

\footnotetext{
${ }^{1}$ Médico Veterinário, Pós-graduando do Departamento de Clínica e Cirurgia Veterinária, Faculdade de Ciências Agrárias Veterinárias (FCAV), Universidade Estadual Paulista (UNESP), Via de acesso Professor Paulo Donato Castellane, s/nº , 14884-900, Jaboticabal, SP. ${ }^{2}$ Médico Veterinário, Professor Doutor- Depto Clínica e Cirurgia Veterinária, FCAV, UNESP, Jaboticabal, SP.

${ }^{3}$ Médico Veterinário, Professor Titular, Departamento de Patologia Veterinária, FCAV, UNESP, Jaboticabal, SP. E-mail: cad@fcav.unesp.br.
} 
ainda, ressecção, colostomia e enteranastomose (STASHAK,1982; RUGGLES \& ROSS, 1991).

Várias técnicas de suturas têm sido utilizadas nas enterorrafias do cólon descendente, podendo-se empregar padrão aposicional ou invaginante em um ou dois planos (STASHAK, 1982) e são empregados diversos materiais de síntese. Na literatura consultada, consta a utilização de fio de polipropileno multifilamentar (ARCHER $\boldsymbol{e t}$ al., 1988), de polidioxanona (HASSEL \& YARBROUGH, 1998), de categute cromado (d'UTRA VAZ et al., 1993) e fio de poliglactina 910 (RAMEY, 1985, BEARD et al., 1989, SHETA $\boldsymbol{e t}$ al., 1995; LUCAS, 1999). Segundo BEARD et al. (1989) e LUCAS (1999), as suturas realizadas com fio de poliglactina 910 causam reação inflamatória granulomatosa com presença de células gigantes.

$\mathrm{O}$ emprego de adesivo tecidual em cirurgia vem sendo descrito desde 1958, quando Block usou um adesivo epoxi para reunir tecido ósseo fraturado (INOU, 1962). Porém, o adesivo tecidual mais utilizado é o cianoacrilato, que a partir da década de 60, foi objeto de experimentos envolvendo o trato gastrintestinal (INOU, 1962; WEILBAECHER et al., 1964; LINN et al., 1966; MATSUMOTO et al., 1969; PLAPLER et al.,1983). Os cianoacrilatos são adesivos de polimerização rápida, que se degradam entre 3 e 6 meses (HEALEY et al., 1965; LAMBORN et al., 1970) e providos de ação hemostática (SILVER, 1976).

Os estudos relacionados à utilização de adesivo tecidual no trato gastrintestinal são contraditórios. INOU (1962), WEILBAECHER et al. (1964) e MATSUMOTO et al. (1969) evidenciaram a ocorrência de alta taxa de óbito em cães submetidos a anastomoses intestinais com cianoacrilato. Contrariamente, LINN et al. (1966) obtiveram reação inflamatória menor e continuidade melhor da parede intestinal com o adesivo tecidual do que com anastomose convencional.

PLAPLER et al. (1983), comparando anastomoses de intestino delgado de murinos com cianoacrilato e fio de polipropileno, citaram como vantagens do adesivo a facilidade de aplicação, a redução do tempo operatório e a melhor vedação da anastomose. Referiram que o cianoacrilato provocou inflamação granulomatosa com células gigantes, que foi considerada maior aos 30 do que aos 60 dias.

O objetivo deste trabalho foi comparar o butil-2-cianoacrilato e a sutura aposicional convencional com o uso fio de poliglactina 910 no cólon descendente de eqüinos. Para tal, efetuaram-se avaliações seqüenciais das lesões, mediante exames macroscópico e histopatológico, complementando-se com observações feitas à microscopia eletrônica de varredura.

\section{MATERIAL E MÉTODOS}

Foram utilizados 15 eqüinos, seis machos castrados e nove fêmeas, sem raça definida, adultos, com três a cinco anos de idade e hígidos, separados em cinco tempos de observação, com três animais cada. No período pré-cirúrgico, foi realizado exame clínico em todos os animais. Os eqüinos foram colocados em jejum alimentar e hídrico de 24 e 12 horas, respectivamente.

A pré-anestesia constou de cloridrato de xilazina $^{\mathrm{a}}(1,1 \mathrm{mg} / \mathrm{kg})$; após 10 minutos, os eqüinos foram a decúbito sob efeito do éter gliceril guaiacol ${ }^{\mathrm{b}}$ $(110 \mathrm{mg} / \mathrm{kg})$ e a indução anestésica foi obtida com tiopental sódico $^{c}(12,5 \mathrm{mg} / \mathrm{kg})$; todos os fármacos foram administrados por via intravenosa. Os animais foram intubados com sonda orotraqueal e mantidos sob anestesia geral inalatória pelo halotano ${ }^{\mathrm{d}}$ vaporizado em oxigênio, em circuito semi-fechado.

A intervenção cirúrgica foi realizada com os eqüinos em decúbito lateral direito, após tricotomia e anti-sepsia da fossa paralombar com solução de polivinilpirrolidona-iodo e e álcool iodado a 5\%. A laparotomia pelo flanco esquerdo seguiu a indicação de TURNER \& McILWRAITH (1982). O cólon descendente foi exteriorizado até que o ligamento duodenocólico (SISSON, 1986) fosse identificado e o conteúdo intestinal propulsionado manualmente no sentido aboral. Os locais das enterotomias escolhidos foram delimitados e o órgão isolado com compressas estéreis. Foram realizadas duas enterotomias de cinco centímetros de extensão cada, distanciadas $20 \mathrm{~cm}$ uma da outra, sendo a primeira feita a aproximadamente $40 \mathrm{~cm}$ aboral ao ligamento duodenocólico, de acordo com ARCHER et al. (1988). As enterotomias foram realizadas com bisturi, em sentido longitudinal sobre a 'teniae coli', conforme BEARD et al. (1989). A enterorrafia da primeira ferida, localizada oralmente, foi efetuada com quatro pontos de sustentação em padrão interrompido perfurante distanciados $1,0 \mathrm{~cm}$ entre si usando fio de poliglactina $910^{\mathrm{f}} \mathrm{n}^{\mathrm{o}} 0$, e pela aplicação de uma camada fina de adesivo tecidual à base de cianoacrilato $^{g}$ de permeio aos pontos na fenda serosa, com o objetivo de obter-se a justaposição das bordas da ferida (Figura 1-A). A segunda ferida intestinal, de localização aboral, foi suturada com padrão interrompido perfurante total aposicional, usando fio de poliglactina $910 \mathrm{n}^{\mathrm{o}} 0$, mantendo um espaçamento de $3,0 \mathrm{~mm}$ entre os pontos (Figura 1A). Durante todo o procedimento cirúrgico, o cólon 

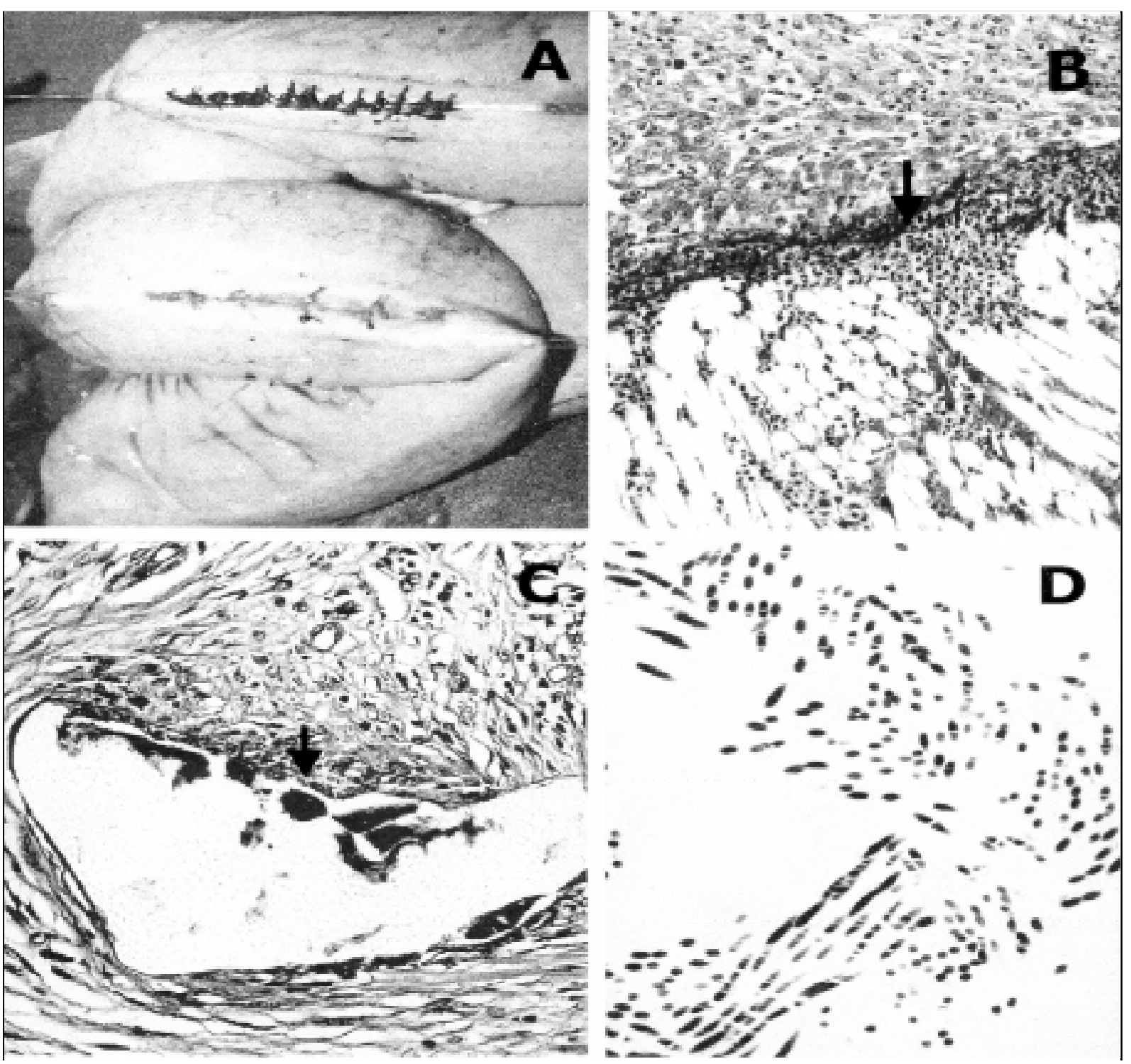

Figura 1 - Fotografia das enterorrafias aposicional e com cianoacrilato (A); Fotomicrografia de corte transversal do cólon descendente submetido a enterorrafia aposicional aos 15 dias de pós-operatório. Observar presença de PMN ao redor do fio de sutura (seta). Animal $n^{\circ}$ 7. HE. Obj. 20X (B); Fotomicrografia de corte transversal do cólon descendente submetido a enterorrafia com cianoacrilato aos 35 dias de pós-operatório. Notar células gigantes (seta) ao redor do adesivo tecidual. Animal n ${ }^{\circ}$ 2. HE. Obj. 20X (C); Fotomicrografia de corte transversal do cólon descendente submetido a enterorrafia aposicional aos 35 dias de póscirúrgico. Visualizar filamentos do fio de poliglactina 910. Animal n 12. AT. Obj. 10X (D).

descendente foi mantido úmido com solução de cloreto de sódio ${ }^{\mathrm{h}} 0,9 \%$ a $37^{\circ} \mathrm{C}$. Terminadas as suturas, o cólon descendente foi recolocado na cavidade peritoneal e a laparorrafia foi feita de acordo com a técnica preconizada por TURNER \& McILWRAITH (1982), utilizando-se fio de náilon ${ }^{\mathrm{i}}$ $\mathrm{n}^{\mathrm{o}} 1$.

No período pós-cirúrgico imediato, os animais receberam penicilina procaína $^{\mathrm{j}}$ (22.000UI/kg a cada 12 horas) e sulfato de gentamicina $^{\mathrm{k}}(6,6 \mathrm{mg} / \mathrm{kg}$ a cada 24 horas), de acordo com LUCAS (1999), ambas por via intramuscular, durante cinco dias consecutivos, com exceção do grupo experimental de três dias de observação pós-operatória, que recebeu esta medicação somente nesse período.

O acompanhamento clínico no período pós-cirúrgico incluiu avaliações das freqüências cardíaca e respiratória, coloração das mucosas oral e conjuntivas palpebral e bulbar, tempo de preenchimento capilar, temperatura retal e auscultação abdominal a cada 12 horas, nos dias 
subseqüentes ao ato cirúrgico até o final do período de avaliação estabelecido para cada grupo.

$\mathrm{Na}$ ferida cirúrgica, foram feitos curativos diários com polivinilpirrolidona-iodo até a cicatrização completa e extração dos pontos aplicados na pele, excetuando-se os animais de observação de três e sete dias pós-cirúrgicos, que foram assim tratados até o sacrifício, o qual foi efetuado aos três, sete, 14, 35 ou 70 dias pósoperatórios para inspeção da cavidade abdominal e colheita de fragmentos do cólon menor para exames histopatológico e de microscopia eletrônica de varredura.

Os fragmentos intestinais colhidos para microscopia óptica (MO) foram mantidos planos em papel espesso mediante colocação de grampos e imediatamente imersos em líquido de Bouin por 24 horas para fixação e, em seguida, colocados em álcool $70 \%$ até o início do processamento. A técnica empregada foi a de inclusão em parafina, sendo os cortes seriados de $6 \mu \mathrm{m}$ de espessura cada, corados pela hematoxilina-eosina (HE) ou azul de toluidina (AT), segundo BEHMER et al. (1976). A coloração de AT teve o propósito de visualizar o fio de poliglactina 910, conforme CATTELAN et al. (1988).

Os fragmentos intestinais colhidos para microscopia eletrônica de varredura (MEV), também mantidos planos em papel espesso, foram fixados em glutaraldeído a $4 \%$ em solução tamponada de fosfatos, $\mathrm{pH} 7,2$, por período superior a 24 horas, à temperatura de $4^{\circ} \mathrm{C}$. Após a fixação, o material foi processado para observação e registro eletromicrográfico em microscópio eletrônico de varredural.

\section{RESULTADOS E DISCUSSÃO}

A via de acesso pelo flanco esquerdo do animal possibilitou exteriorização e manipulação adequadas do cólon descendente, o que também foi obtido por LUCAS (1999). Contudo, RAMEY (1985), ARCHER $\boldsymbol{e}$ t al. (1988), BEARD $\boldsymbol{e} \boldsymbol{t} \boldsymbol{a l}$. (1989), RUGGLES \& ROSS (1991), SHETA $\boldsymbol{e}$ t al. (1995) e HASSEL \& YARBROUGH (1998) preconizaram o acesso pela linha média ventral, relatando maior dificuldade para exposição do cólon descendente por outras vias, pelo fato do mesocólon ser curto.

O segmento intestinal utilizado nesta investigação, o cólon descendente, localiza-se no quadrante dorsal esquerdo da cavidade abdominal e representa a continuação caudal do cólon transverso (SISSON, 1986). A referência anatômica utilizada para delimitar as enterotomias, o ligamento duodenocólico, foi rapidamente identificada após leve tensão na porção oral do cólon descendente.

$\mathrm{O}$ adesivo tecidual empregado foi o butil2-cianoacrilato, que polimerizou entre 30 e 60 segundos e reduziu a ferida cirúrgica, corroborando HEALEY et al. (1965), LINN et al. (1966) e LAMBORN $\boldsymbol{e t}$ al. (1970). Nas feridas em que foi usado esse adesivo, ocorreu hemorragia discreta (Figura 1-A), possivelmente, devido à ação hemostática do produto, conforme relatou SILVER (1976). Também se observou adequada aposição das bordas da ferida, o que está de acordo com LINN $\boldsymbol{e} t$ al. (1966) e PLAPLER $\boldsymbol{e t}$ al. (1983).

$\mathrm{Na}$ sutura intestinal aposicional ocorreu hemorragia maior quando comparada à ferida reduzida com cianoacrilato (Figura 1-A), todavia o espaçamento de $3 \mathrm{~mm}$ entre os pontos foi suficiente para proporcionar justaposição das bordas da ferida, concordando com LUCAS (1999). O fio de poliglactina 910 mostrou-se resistente, de fácil manuseio, visível em meio aos tecidos e seguro para manter os nós, observações também feitas por RAMEY (1985), BEARD $\boldsymbol{e t}$ al. (1989), SHETA $\boldsymbol{e} t$ al. (1995) e LUCAS (1999).

Embora não tenha sido mensurado, o tempo operatório foi notavelmente menor na redução da ferida com cianoacrilato, concordando com LINN et al. (1966), MATSUMOTO et al. (1969), LAMBORN et al. (1970), PLAPLER $\boldsymbol{e t}$ al. (1983), que relataram redução do tempo operatório com o uso do adesivo.

Os eqüinos receberam antibioticoterapia devido às enterotomias executadas que poderiam sofrer contaminação bacteriana (STASHAK, 1982). Conforme foi preconizado por LUCAS (1999), a antibioticoterapia foi feita com penicilina procaína e sulfato de gentamicina. BEARD et al. (1989) e d'UTRA VAZ et $\boldsymbol{a l}$. (1993) também utilizaram antibióticos durante o período experimental, ao contrário de ARCHER et al. (1988).

Não ocorreram alterações significativas nas funções vitais, exceto na motilidade intestinal, observando-se evolução clínica adequada, assemelhando-se aos relatos de BEARD $\boldsymbol{e t}$ al. (1989), d'UTRA VAZ et al. (1993) e LUCAS (1999). O padrão fisiológico da motilidade intestinal restabeleceu-se entre 12 e 24 horas pós-cirúrgicas, diferindo do observado por BEARD et al. (1989) e SHETA et al. (1995), que relataram normalização da motilidade entre 4 e 6 horas após o ato operatório. As fezes apresentaram-se com aspecto e consistência normais, exceto num animal que apresentou diarréia no $20^{\circ}$ dia pós-operatório, o que também foi citado por RUGGLES \& ROSS (1991), nos primeiros dias após a intervenção cirúrgica. A ocorrência desse 
caso isolado de diarréia, provavelmente, tenha sido de natureza dietética, pois o paciente recuperou-se sem que qualquer medicação específica fosse administrada.

Com exceção dos pacientes sacrificados aos três e sete dias, a cicatrização da parede abdominal ocorreu por primeira intenção, conforme os resultados de BEARD et al. (1989), SHETA et al. (1995) e LUCAS (1999). Na avaliação necroscópica, o adesivo foi visualizado junto a serosa intestinal no terceiro e sétimo dias de pós-operatório. $\mathrm{Na}$ literatura consultada, não se encontrou nenhuma alusão a este fato. Macroscopicamente, LUCAS (1999) encontrou o fio de poliglactina 910 até o $35^{\circ}$ dia de observação, contudo, neste experimento o período de avaliação foi maior, e o fio esteve presente até o $70^{-}$dia.

Pela necropsia contatou-se que nas feridas reduzidas com cianoacrilato ocorreram aderências em sete casos $(46,66 \%)$ sendo três $(20 \%)$ no epíploo, dois $(13,33 \%)$ no mesocólon, um $(6,66 \%)$ no cólon menor e um $(6,66 \%)$ em abscesso. $\mathrm{Na}$ enterorrafia com padrão aposicional, ocorreram aderências em oito pacientes $(53,33 \%)$ sendo quatro $(26,66 \%)$ no epíploo, dois $(13,33 \%)$ no mesocólon, um $(6,66 \%)$ no cólon descendente e um $(6,66 \%)$ em abscesso. Aderências também foram encontradas por MATSUMOTO $\boldsymbol{e} \boldsymbol{t} \boldsymbol{a l}$. (1969) e PLAPLER $\boldsymbol{e} \boldsymbol{t} \boldsymbol{a l}$. (1983) quando compararam técnicas de suturas convencionais e redução com cianoacrilato. Contrariamente, LINN et al. (1966) não obtiveram aderências nas anastomoses intestinais de cães no grupo com sutura aposicional e $88 \%$ do grupo em que utilizaram o adesivo tecidual. STASHAK (1982) e LUCAS (1999) relataram que a sutura aposicional empregada em seu estudo causou maior número de aderências quando comparada a uma sutura invaginante em cólon descendente de eqüinos. BEARD et al. (1989), utilizando fio de poliglactina 910, também mencionaram a ocorrência de aderências. RAMEY (1985), que comparou suturas com materiais convencionais e agrafes, mencionou menor número de aderências nas enterorrafias com agrafes, indicando que a reatividade do material de sutura é uma causa importante de aderências, talvez de maior significado que o padrão de sutura.

Um paciente submetido à sutura aposicional apresentou abscesso com $3 \mathrm{~cm}$ de diâmetro, localizado na serosa do cólon descendente. Noutro, submetido à enterorrafia com cianoacrilato observou-se abscesso ovalado de aproximadamente $3 \times 2 \mathrm{~cm}$ situado na parede do cólon menor. Nessa região foi observada descontinuidade de $3 \mathrm{~mm}$ da ferida intestinal. Esses abscessos ocorreram devido a falha técnica na execução da enterorrafia, aliada à predisposição desse segmento intestinal à peritonite e rupturas após manipulação e enterotomia (HASSEL \& YARBROUGH, 1998). O abscesso observado junto ao cianoacrilato também pode ter ocorrido por adesão insuficiente do produto (INOU, 1962; WEILBAECHER $\boldsymbol{e}$ al ., 1964; MATSUMOTO et al., 1969).

Os achados anatomopatológicos associados aos da MO mostraram que, apesar da camada mucosa estar descontínua no $3^{0}$ dia, já ocorria proliferação epitelial nas bordas. A regeneração dessa camada foi vizualizada no $7^{\underline{0}}$ dia de pós-operatório na maioria dos animais e em ambas as técnicas estudadas. Pela MEV, havia uma depressão da área operada em epitelização (Figura 2A). LUCAS (1999), ao comparar padrões de sutura aposicional e invaginante, no cólon descendente de eqüinos, observou a continuidade da mucosa a partir do $7^{\underline{0}}$ dia pós-operatório. RAMEY (1985), ao empregar sutura de eversão e padrão invaginante e SHETA et al. (1995), que compararam as suturas de Gambee e Lembert, fizeram essa constatação no $10^{\circ}$ dia. Pela MEV, verificou-se que a área operada permaneceu com depressão na mucosa até o $70^{\circ}$ dia, entretanto, isso não provocou qualquer complicação adicional.

Nas duas técnicas comparadas nesta pesquisa, a fibroplasia ocorreu no $3^{-}$dia, tornando-se mais intensa a partir do $7^{\circ}$ dia, quando se observou elevada vascularização. INOU (1962) verificou fibrose aos 14 dias, após utilizar metil-2cianoacrilato em intestino delgado de cães. WEILBAECHER et al. (1964), realizando anastomoses em intestinos delgado e grosso com o adesivo metil-2-cianoacrilato em cães, notaram que a partir do $2^{-}$ou $3^{-}$dias já havia vascularização; que na terceira semana essa foi diminuindo e o tecido de granulação foi se diferenciando. Pela $\mathrm{MEV}$, as camadas do órgão estudado estavam bem alinhadas e compactas a partir do $35^{\circ}$ dia, evidenciando a reparação cicatricial.

Da mesma forma que relatado por WEILBAECHER et al. (1964), o adesivo tecidual mostrou-se refringente à $\mathrm{MO}$ e de aspecto amorfo na MO e MEV (Figuras 1-C e 2-B).

Similarmente às observações de LINN $\boldsymbol{e t}$ al. (1966), a enterorrafia com cianoacrilato causou reação inflamatória discreta. Até o $15^{\circ}$ dia havia pequena quantidade de polimorfonucleares (PMN) e mononucleares (MN). A partir do $35^{\mathrm{o}}$ dia, observaram-se células gigantes ao redor do adesivo (Figura 1-C), diferindo dos achados de WEILBAECHER et al. (1964), que não as evidenciaram após a terceira semana, ocasião em que ocorreu o desaparecimento do adesivo. 


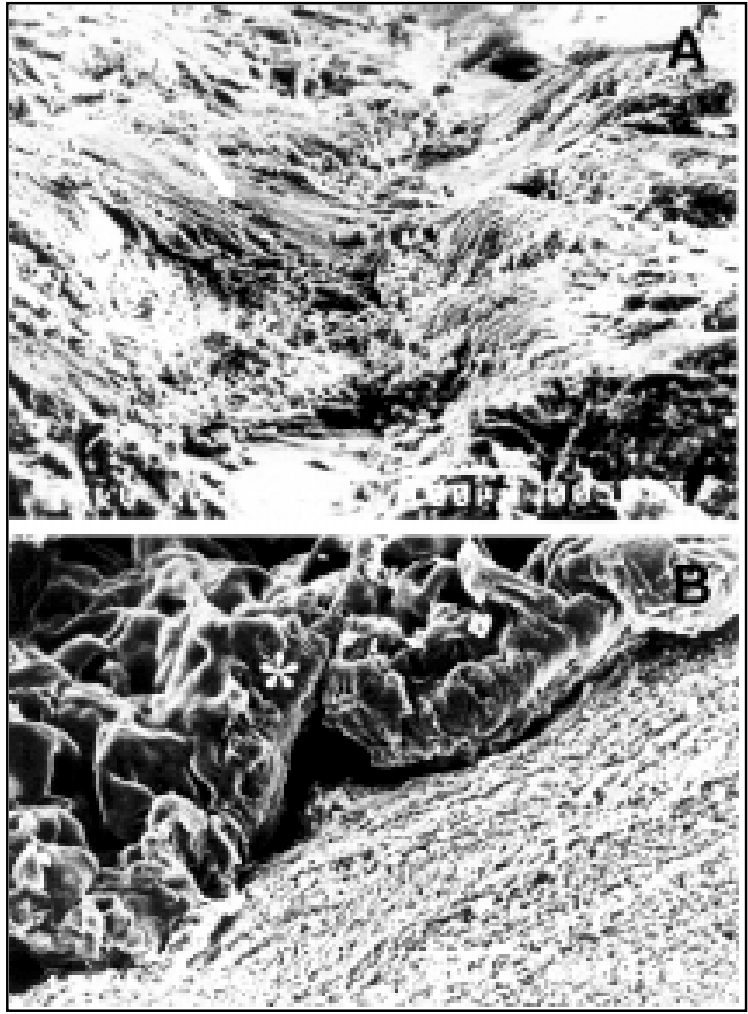

Figura 2 - Eletromicrografia do cólon descendente de eqüino submetido a enterorrafia com cianoacrilato aos $15 \mathrm{di}-$ as. Observar epitelização da mucosa e depressão na região operada (seta). Animal no 9. 200X (A). Eletromicrografia do cólon descendente de eqüino submetido a enterorrafia com cianoacrilato aos 3 dias. Notar a superfície rugosa do adesivo (*) junto às camadas musculares do intestino. Animal $\mathrm{n}^{\circ} 1.350 \mathrm{X}$ (B)

A fina camada de adesivo que foi aplicada sobre a serosa penetrou pela incisão cirúrgica, pois foi observada nas camadas musculares do cólon descendente tanto na MO quanto na MEV (Figura 2B). Entretanto, isso não impediu a cicatrização do órgão.

Até 70 dias de avaliação, o adesivo foi visualizado na $\mathrm{MO}$ e MEV, o que permitiu concordar com PLAPLER et al. (1983) que efetuaram observações até os 60 dias de pós-operatório, notando a presença do adesivo. WEILBAECHER et al. (1964) relataram que o adesivo desapareceu após a terceira semana, porém os autores trabalharam com cianoacrilato de cadeia curta, que sofre degradação com maior rapidez. Segundo LAMBORN et al. (1970), que compararam três tipos de cianoacrilato em ratos, o metil-cianoacrilato foi degradado rapidamente, enquanto o butil e isobutil-cianoacrilato persistiram por 16 semanas. MATSUMOTO $\boldsymbol{e}$ t al. (1969), realizando anastomose em intestino delgado de cães verificaram que o butil-cianoacrilato permaneceu no tecido por 16 meses e SILVER (1976) citou que o adesivo pode permanecer por até 2 anos no local em que é aplicado.

$\mathrm{Na}$ sutura aposicional, observou-se inflamação intensa, com grande infiltração de PMN ao redor do fio de poliglactina 910 até o $15^{\mathrm{O}}$ dia (Figura 1-B). LUCAS (1999), ao comparar dois padrões de sutura com poliglactina 910 no cólon descendente de eqüinos, notou maior quantidade de PMN no padrão aposicional a partir do $3^{\underline{0}}$ dia. Inicialmente havia inflamação intensa que se tornou moderada aos 14 dias.

Neste experimento, as $\mathrm{MN}$, raras na fase inicial, foram aumentando gradativamente e, desde o $7^{\underline{0}}$ até o $70^{\circ}$ dia, observaram-se células gigantes ao redor do fio, denotando inflamação granulomatosa do tipo corpo estranho, fato também evidenciado por LUCAS (1999).

O fio de poliglactina 910 estava presente e sendo fagocitado no $35^{\circ}$ dia, comprovando os estudos de BEARD et al. (1989) e LUCAS (1999). SHETA et al. (1995) confirmaram esse achado até o $50^{\circ}$ dia, concluindo a necessidade de um tempo maior de observação. No presente estudo, notou-se resquícios de fio em um animal aos 70 dias e a visualização do fio de poliglactina 910 (Figura 1-D) foi efetiva pela coloração de AT (BEHMER $\boldsymbol{e t}$ al., 1976), corroborando as observações de CATTELAN et al. (1988), feitas a respeito do fio de ácido poliglicólico em cólon de cão.

\section{CONCLUSÕES}

$\mathrm{O}$ fio de poliglactina 910 e o adesivo butil-2-cianoacrilato são apropriados para uso em enterorrafias de cólon descendente de eqüinos. O fio de poliglactina 910 provoca inflamação inicial mais intensa que o cianoacrilato e, mais tardiamente, ambos causam inflamação granulomatosa do tipo corpo estranho observada, primeiramente, junto ao fio de poliglactina 910 ( $7^{\circ}$ dia $)$ e, a partir do $35^{\circ}$ dia, ao redor do cianoacrilato.

\section{FONTES DE AQUISIÇÃO}

a - Rompun-Bayer- São Paulo, SP

b - Éter Gliceril Guaiacol- Henryfarma Ltda- São Paulo, SP

c - Tiopental- Cristália- Campinas, SP

d - Halotano- Cristália- Campinas, SP

e - Riodeíne Tópico- Indústria Farmacêutica Rioquímica Ltda- São José do Rio Preto, SP

f - Vycril- Ethicon- São José dos Campos, SP

g - Histoacryl- B. Braun- Melsungen- Alemanha

h - Fisiológico Cloreto de Sódio A 0,9\%- JP Indústria Farmacêutica S.A.- Ribeirão Preto, SP

i - Mononylon- Ethicon- São José dos Campos, SP 
j - Agrovet - Ciba- São Paulo, SP

k - Gentrin - Produtos Veterinários Ouro Fino Ltda- Ribeirão Preto, SP

1 - JEOL - Modelo JSM - 5410.

\section{REFERÊNCIAS BIBLIOGRÁFICAS}

ARCHER, R.M., PARSONS, J.C., LINDSAY, W. A., et al. A comparison of enterotomies through the antimesenteric band and sacculation of the small (descending) colon of ponies. Equine Vet J, v.20, n.20, p.406-413, 1988.

BEARD, W.L., ROBERTSON, J.T., GETZY, D.M. Enterotomy technique in the descending colon of the horse - Effect of location and suture pattern. Vet Surg, v.18, n.2, p.135-140, 1989.

BEHMER, O.A., TOLOSA, E.M.C., FREITAS NETO, A.G. Manual de técnicas para histologia normal e patológica. São Paulo : Edart, 1976. 256p.

CATTELAN, J.W., ALESSI, A.C., POLACHINI, J.R. Utilização da sutura extramucosa interrompida com fio de ácido poliglicólico em intestino grosso de cães. Ars Vet, v.4, n.2, p.205-215, 1988.

d'UTRA VAZ, B.B., MARQUES, J.A., LAUS, J.L., et al. Estudo dos efeitos do cloranfenicol sobre a cicatrização intestinal em eqüinos. Ciência Rural, v.23, n.1, p.37-42, 1993.

HASSEL, D.M., YARBROUGH, T.B. A modified teniotomy technique for facilitated removal of descending colon enteroliths in horses. Vet Surg, v.20, n.5, p.320-322, 1998.

HEALEY, J.E., GALLAGER, H.S., MOORE, E.B. Experiences with plastic adhesive in the nonsuture repair of the body tissue. Am J Surg, v.109, n.4, p.416-423, 1965.

INOU, T. Studies on the surgical use of plastic adhesive. Am J Proctol, v.13, n.4, p.219-226, 1962.

LAMBORN, P.B., SOLOWAY, H.B., MATSUMOTO, T. $\boldsymbol{e}$ t al. Comparison of tensile strenght of wounds closed by sutures and cyanoacrylate. Am J Vet Res, v.31, n.1, p.125130,1970 .

LINN, B.S., CECIL, F., CONLY, P., et al. Intestinal anastomosis by invagination and gluing. Am J Surg, v.111, p.197-199, 1966.
LUCAS, F.A. Estudo comparativo entre técnicas de enterorrafias em planos aposicional e invaginante no cólon descendente de eqüinos. Jaboticabal, 1999. 61p. Dissertação (Mestrado em Cirurgia Veterinária) - Faculdade de Ciências Agrárias e Veterinárias, Universidade Estadual Paulista, Jaboticabal, 1999.

MATSUMOTO, T., PANI, K.C., KOVARIC, J.J., et al. Tissue adhesive in intestinal surgery. Am Surg, v.35, n.3, p.210$217,1969$.

PLAPLER, H., MORRELL, A.C., GOLDENBERG, S., $\boldsymbol{e}$ t al. Estudo comparativo das enteroanastomoses realizadas por colagem com cianoacrilato e sutura com polipropileno. Med Cult, v.38, n.2-3, p.46-49, 1983.

RAMEY, D.W. Healing in the small colon of pony: stapling vs. Suturing. In: SYMPOSIUM OF EQUINE COLIC RESEARCH 2, 1985, Athens. Proceedings... Athens: University of Georgia, 1985. p.166-167.

RUGGLES, A.J., ROSS, M.W. Medical and surgical management of small impactation in horses: 28 cases (1984-1989). J Am Vet Med Assoc, v.199, n.12, p.1762-1766, 1991.

SHETA, E.M.E., FARAG, K.A., EL-ZOMOR, S.T., et $\boldsymbol{a l}$. Studies on Gambee and Lembert patterns for closure of small colon enterotomies in equine. Vet Med J, v.43, n.1, p.141$146,1995$.

SILVER, I.A. Tissue adhesives. Vet Rec, v.98, p.405-406, 1976.

SISSON, S. Anatomia dos animais domésticos. Rio de Janeiro: Guanabara-Koogan, 1986. V.1: Sistema digestivo do eqüino:, p.424-465.

STASHAK, T.S. Technique for enterotomy, descompression and intestinal resection/anastomosis. Vet Clin North Am Large Animal Pract, v.4, p.147-165, 1982.

TURNER, A.S., McILWRAITH, C.W. Equine dental and gastrointestinal surgery. Techniques in large animal surgery. Philadelphia: Lea \& Febinger, 1982. p. 211216

WEILBAECHER, D.A., MATHIEU, F.J., COHN Jr., I. Nonsuture intestinal anastomosis. Am J Surg, v.107, p.353360,1964 